\title{
Familial risks in and between stone diseases: sialolithiasis, urolithiasis and cholelithiasis in the population of Sweden
}

\author{
Kari Hemminki ${ }^{1,2^{*}}$, Otto Hemminki ${ }^{3,4}$, Anni I. M. Koskinen ${ }^{5}$, Asta Försti ${ }^{1,2}$, Kristina Sundquist ${ }^{2,6,7}$, \\ Jan Sundquist ${ }^{2,6,7}$ and Xinjun Li ${ }^{2}$
}

\begin{abstract}
Background: According to the literature the three stone diseases, sialolithiasis (SL), urolithiasis (UL) and cholelithiasis (CL) share comorbidities. We assess familial and spouse risks between these stone disease and compare them to familial risks for concordant (same) stone disease.

Methods: Study population including familiar relationships was obtained from the Swedish Multigeneration Register and stone disease patients were identified from nation-wide medical records. Standardized incidence ratios (SIRs) were calculated for 0-83 year old offspring when their first-degree relatives were diagnosed with stone disease and the rates were compared to individuals without a family history of stone disease. Numbers of offspring with SL were 7906, for UL they were 170,757 and for CL they were 204,369.

Results: SIRs for concordant familial risks were 2.06 for SL, 1.94 for UL and 1.82 for CL. SIRs for SL and UL were slightly higher for women than for men. Familial risks between stone diseases were modest. The highest risk of 1.17 was for UL when family members were diagnosed with $\mathrm{CL}$, or vice versa. The SIR for UL was 1.15 when family members were diagnosed with SL. Familial risks among spouses were increased only for UL-CL pairs (1.10).

Conclusions: Familial risks for concordant SL were 2.06 and marginally lower for the other diseases. Familial risks between stone diseases were low but higher than risks between spouses. The data show that familial clustering is unique to each individual stone disease which would imply distinct disease mechanisms. The results cast doubt on the reported comorbidities between these diseases.
\end{abstract}

Keywords: Salivary gland stones, Kidney stones, Ureter stones, Bladder stones, Heritability

\section{Background}

Sialolithiasis (SL) is a condition where a calcified mass (sialolith, salivary calculi or salivary stone) forms within the ducts of salivary glands $[1,2]$. The most common location is the submandibular gland (Warton's duct), while the parotid gland and particularly the sublingual gland are less frequently affected [3]. Reported incidence rates vary but in the Danish patient records the incidence was 7.3 per 100,000 person-years based on medically confirmed cases and doubled when unconfirmed cases were included [4].

\footnotetext{
*Correspondence: k.hemminki@dkfz.de

${ }^{1}$ Division of Molecular Genetic Epidemiology, German Cancer Research Center (DKFZ), Im Neuenheimer Feld 580, D-69120 Heidelberg, Germany ${ }^{2}$ Center for Primary Health Care Research, Lund University, 20502 Malmö, Sweden

Full list of author information is available at the end of the article
}

Risk factors include infections, inflammation, diabetes and Sjögren syndrome [5]. Literature on possible familial risk or genetic predisposition in SL is practically non-existent [6]. Urolithiasis (UL) or urinary tract stone disease covering stones in the kidney (nephrolithiasis), ureter or bladder is a common disease with between 1 and $15 \%$ of people globally affected at some point in their life with the condition and the disease prevalence is increasing $[7,8]$. Stone formation is due to a combination of genetic and environmental factors. Risk factors include high urine calcium levels, obesity, certain foods, some medications, calcium supplements, hyperparathyroidism, gout, diabetes, hypertension, not drinking enough fluids and family history $[8,9]$. Cholelithiasis $(\mathrm{CL})$ or gallstone disease is the most common of these three and some 10 to $20 \%$ of the populations in western

(c) The Author(s). 2018 Open Access This article is distributed under the terms of the Creative Commons Attribution 4.0 International License (http://creativecommons.org/licenses/by/4.0/), which permits unrestricted use, distribution, and 
counties develop gallstones and the condition is becoming more widespread due to the increasing prevalence of risk factors such as obesity and physical inactivity [10, 11]. Other risk factors are female sex, high age, pregnancy, certain ethnic background, family history and genetics $[10,12]$.

According to X-ray microanalysis stones in SL and UL share elemental composition and calcium salts are the main inorganic chemical constituents [1]. In contrast, gallstones are made of organic compounds, the most common ones are cholesterol stones and rarer ones are bilirubin stones [13]. Several epidemiological studies have observed comorbidities between these stone diseases. Case-control studies from Taiwan found significant increases for nephrolithiasis (odds ratio, OR 4.74) and CL (OR 2.20) in SL patients compared to controls $[14,15]$. A similar study from the same source found a risk of renal stones (OR 1.68) in CL patients [16]. A prospective US study found reciprocal risks for renal stones and CL in the OR range of 1.2 to 1.6 in men and women [17]. Although the above and other studies make a case for true comorbidities among stone diseases, surveillance bias is a vicious intervening factor which is extremely difficult to avoid or correct for in diseases for which prior medical contacts have taken place [18].

Comorbidity for two diseases may be explained by shared environmental or genetic factors. We have a possibility to estimate the possible role of environmental factors among spouses, and we have an excellent possibility to address the possible role of genetic factors as we have data on all family relationships in Sweden [19]. In view of individual and medical importance of the three stone diseases it would be of outmost relevance to verify the possible comorbidities in a setting where surveillance bias might not operate. Sharing of familial risks between the stone disease would provide a mechanistic rationale that some genetic and/or shared environmental factors would also pose an individual risk for comorbidity. We use Swedish national health service and family records to assess familial risks for the three stone diseases. We assess spouse correlations between these diseases in order to quantify the possible risks through cohabitation.

\section{Methods}

Family relationships were obtained from the Multigeneration Register, containing the Swedish population in families. 'The offspring generation' was born after 1931 and by year 2015 oldest offspring reached age 83 years; siblings could be defined only in the offspring generation. Stone diseases were identified using the nationwide Swedish Hospital Discharge Register (1987-2015) and the Outpatient Register (2001-2015). The first stone diagnosis was considered and a patient was only entered once, in order to avoid surveillance bias. Only $9.6 \%$ of SL patients were later diagnosed with UL or CL, and for UL and CL patients the proportions with multiple stone diseases were even lower. In a separate analysis, risks were calculated to offspring whose family members were diagnosed with a single stone disease or with multiple stone diseases. Information from the registers was linked at the individual level via the national 10-digit civic registration number. In the linked dataset, civic registration numbers were replaced with serial numbers to ensure anonymity. Revisions 9 (1987-1996) and 10 (1997-) of the International Classification of Diseases were used to identify SL, UL and CL patients.

Age-adjusted incidence rates for patients identified from the inpatient and outpatient registers were calculated per 100,000 person years of the population. For incidence trend plots only inpatient data were used as only these data were available from 1987 to 2015 .

Familial risk was considered for offspring with a stone disease whose first-degree relatives (parent or siblings) were diagnosed with the same (concordant) or different (discordant) stone disease. Standardized incidence ratios (SIRs) were calculated as the ratio of observed to expected number of cases. The expected numbers were calculated for all individuals without a history of the defined stone disease, and the rates were standardized by 5-year-age, gender, period ( 5 years group), socioeconomic status and residential area. The expected rates were derived from the present dataset covering the Swedish population. The 95\% confidence interval $(95 \% \mathrm{CI})$ of the SIR was calculated assuming a Poisson distribution.

In order to assess environmental risk factors for familial stone disease, we determined SIRs for spouses. The period

Table 1 Population and number of cases of SL, UL and CL in offspring and parents

\begin{tabular}{|c|c|c|c|c|c|c|}
\hline & \multicolumn{2}{|l|}{ SL } & \multicolumn{2}{|l|}{ UL } & \multicolumn{2}{|l|}{$\mathrm{CL}$} \\
\hline & Offspring & Parents & Offspring & Parents & Offspring & Parents \\
\hline Total population & $8,850,394$ & $8,090,648$ & $8,850,394$ & $8,090,648$ & $8,850,394$ & $8,090,648$ \\
\hline \multicolumn{7}{|l|}{ Diagnosis of events } \\
\hline No. of events & 7906 & 8241 & 170,757 & 219,354 & 204,369 & 309,561 \\
\hline Mean age at diagnosis & $43.8 \pm 16.9$ & $51.7 \pm 16.8$ & $47.8 \pm 15.5$ & $54.9 \pm 16.8$ & $47.1 \pm 14.7$ & $57.3 \pm 18.2$ \\
\hline Median age & 45 & 52 & 49 & 55 & 47 & 58 \\
\hline Incidence rate per 100,000 person years ${ }^{a}$ & 4.1 & 3.6 & 94.2 & 90.5 & 111.4 & 120.8 \\
\hline
\end{tabular}

${ }^{a}$ Age adjusted for European standardized population, $S L$ sialolithiasis, UL urolithiasis, $C L$ cholelithiasis 

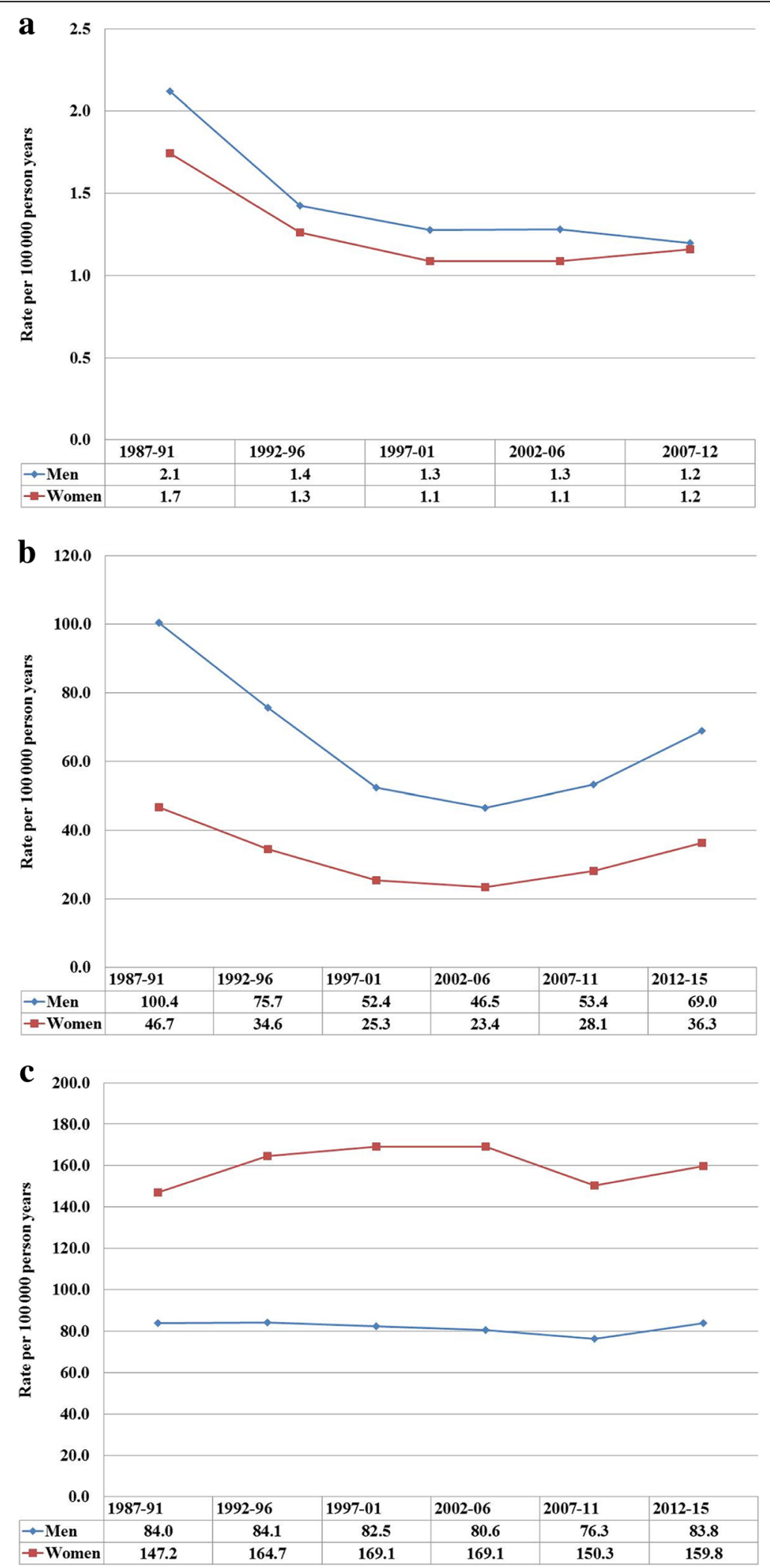

Fig. 1 Age adjusted incidence rates (per 100,000 person years) for sialolithiasis (a), urolithiasis (b) and cholelithiasis (c) for Swedish inpatient during 1987 to 2015 
Table 2 Concordant familial risk of $\mathrm{SL}, \mathrm{UL}$, and $\mathrm{CL}$

\begin{tabular}{|c|c|c|c|c|c|c|c|c|c|c|c|c|}
\hline \multirow{3}{*}{$\frac{\text { Family history }}{\mathrm{SL}}$} & \multicolumn{4}{|l|}{ Men } & \multicolumn{4}{|c|}{ Women } & \multicolumn{4}{|l|}{ All } \\
\hline & \multirow{2}{*}{$\begin{array}{l}0 \\
31\end{array}$} & \multirow{2}{*}{$\begin{array}{l}\text { SIR } \\
1.95\end{array}$} & \multicolumn{2}{|c|}{$95 \% \mathrm{Cl}$} & \multirow{2}{*}{$\begin{array}{l}0 \\
39\end{array}$} & \multirow{2}{*}{$\begin{array}{l}\text { SIR } \\
2.15\end{array}$} & \multicolumn{2}{|c|}{$95 \% \mathrm{Cl}$} & \multirow{2}{*}{$\begin{array}{l}0 \\
70\end{array}$} & \multirow{2}{*}{$\begin{array}{l}\text { SIR } \\
2.06\end{array}$} & \multicolumn{2}{|c|}{$95 \% \mathrm{Cl}$} \\
\hline & & & 1.32 & 2.77 & & & 1.53 & 2.94 & & & 1.60 & 2.60 \\
\hline UL & 19,234 & 1.91 & 1.88 & 1.94 & 11,221 & 1.99 & 1.95 & 2.02 & 30,455 & 1.94 & 1.92 & 1.96 \\
\hline$C L$ & 15,534 & 1.82 & 1.79 & 1.85 & 33,423 & 1.81 & 1.79 & 1.83 & 48,957 & 1.82 & 1.80 & 1.83 \\
\hline
\end{tabular}

Bold type: $95 \% \mathrm{Cl}$ does not include 1.00

$O$ observed number of cases, SIR standardized incidence ratio, $C l$ confidence interval, $S L$ sialolithiasis, $U L$ urolithiasis, $C L$ cholelithiasis

at risk for spouses was defined to start at the birth year of their first common child or at the first year that they were registered as living in the same address, whichever came first. The follow-up was terminated at stone disease diagnosis, death or when spouses no longer lived in the same address [20].

The study was approved by the Regional Ethical Review Board of Lund University (no. 2012/795).

\section{Results}

In Table 1 we show characteristics of the populations used. The total Swedish population used for the study included 8.85 million individuals in the offspring generation and 8.09 million in the parental generation. Case numbers in the two generations were around 8000 for SL, around 200,000 for UL, and 200,000 for CL in offspring and over 300,000 for $\mathrm{CL}$ in parents. The median ages (i.e., age at first hospital contact) for all stone disease were in the 40 s for offspring and in the 50s for parents. Incidence rates per 100,000 person years were in offspring and parents 4.1 and 3.6 for SL, 94.2 and 90.5 for UL, and 111.4 and 120.8 for CL.

Incidence trends for inpatients are shown in Fig. 1. Male rate were higher than female rates for SL and UL but for $\mathrm{CL}$ the opposite was the case. Note that the incidence in Fig. 1 is lower for SL and UL than the rates cited in Table 1 because for these diseases a large proportion of diagnoses originated from the outpatient register (see Methods).

Familial risks are shown in Table 2 for offspring when their parents were diagnosed with the same (concordant) stone disease. The overall familial risks were quite similar, 2.06 for SL, 1.94 for UL and 1.82 for CL. SIRs for SL and UL were slightly higher for women than for men.
Discordant familial risks are shown in Table 3. The SIRs for both sexes were increased for all stone disease pairs with the exception of risk in SL when family members were diagnosed with UL. The highest risk of 1.17 was for UL when family members were diagnosed with $\mathrm{CL}$, or vice versa. The SIR UL was 1.15 when family members were diagnosed with SL. For women 5 pairs were increased compared to only 2 pairs for men. The SIRs were equally high for men and women for UL-CL and CL-UL.

Familial risks were calculated to offspring whose family members were diagnosed with a single stone disease or with multiple stone diseases (Table 4). As the family history of multiple stone diseases was rare, the SIRs for offspring with a family history of a single stone disease were essentially the same as those without specification of family history as shown in Table 2. SIRs for UL and CL were significantly lower for offspring with a family history of multiple stone diseases compared to those with a family history of a single stone disease.

Familial risks for the pairs of stone diseases among spouses are shown in Table 5. The overall risk (1.10) was increased only for UL-CL pairs. The SIR for SL in husbands was 1.26 when wives were diagnosed with UL, and conversely it was 1.26 for in wives when husbands were diagnosed with SL.

\section{Discussion}

The available literature, cited in Introduction, describes comorbidities between the three stone diseases SL, UL and CL. However, as chronic comorbidities involve multiple medical examinations, risk estimation may be subject to surveillance bias [18]. Comorbidities may be caused by

Table 3 Familial SIR of SL, UL, and CL

\begin{tabular}{|c|c|c|c|c|c|c|c|c|c|c|c|c|c|}
\hline \multirow{3}{*}{$\begin{array}{l}\text { Risk in } \\
\text { offspring }\end{array}$} & \multirow{3}{*}{$\begin{array}{l}\text { Family } \\
\text { history }\end{array}$} & \multicolumn{4}{|l|}{ Men } & \multicolumn{4}{|c|}{ Women } & \multicolumn{4}{|l|}{ All } \\
\hline & & \multirow{2}{*}{$\begin{array}{l}0 \\
398\end{array}$} & \multirow{2}{*}{$\begin{array}{l}\text { SIR } \\
1.04\end{array}$} & \multicolumn{2}{|c|}{$95 \% \mathrm{Cl}$} & \multirow{2}{*}{$\begin{array}{l}0 \\
436\end{array}$} & \multirow{2}{*}{$\begin{array}{l}\text { SIR } \\
1.03\end{array}$} & \multicolumn{2}{|c|}{$95 \% \mathrm{Cl}$} & \multirow{2}{*}{$\begin{array}{l}0 \\
834\end{array}$} & \multirow{2}{*}{$\frac{S I R}{1.04}$} & \multicolumn{2}{|c|}{$95 \% \mathrm{Cl}$} \\
\hline & & & & 0.94 & 1.15 & & & 0.94 & 1.13 & & & 0.97 & 1.11 \\
\hline$S L$ & $\mathrm{CL}$ & 572 & 1.06 & 0.97 & 1.15 & 678 & 1.14 & 1.05 & 1.23 & 1250 & 1.10 & 1.04 & 1.16 \\
\hline UL & $S L$ & 494 & 1.09 & 0.99 & 1.19 & 340 & 1.27 & 1.13 & 1.41 & 834 & 1.15 & 1.08 & 1.21 \\
\hline UL & $\mathrm{CL}$ & 5410 & 1.17 & 1.14 & 1.21 & 3316 & 1.16 & 1.12 & 1.20 & 8726 & 1.17 & 1.14 & 1.19 \\
\hline$C L$ & $S L$ & 267 & 1.03 & 0.91 & 1.16 & 714 & 1.18 & 1.09 & 1.27 & 981 & 1.14 & 1.07 & 1.21 \\
\hline $\mathrm{CL}$ & UL & 7379 & 1.17 & 1.14 & 1.20 & 16,445 & 1.17 & 1.15 & 1.19 & 23,824 & 1.17 & 1.16 & 1.19 \\
\hline
\end{tabular}

Bold type: $95 \% \mathrm{Cl}$ does not include 1.00

O observed number of cases, SIR standardized incidence ratio, $C l$ confidence interval; SL sialolithiasis, UL urolithiasis, CL cholelithiasis 
Table 4 Concordant familial risk of $S L$, UL, and CL for individuals with a family member diagnosed with a single or multiple stone diseases

\begin{tabular}{llllll}
\hline & Family history of stone diseases & $\mathrm{O}$ & $\mathrm{SIR}$ & \multicolumn{2}{l}{$95 \% \mathrm{Cl}$} \\
\hline $\mathrm{SL}$ & Only SL & 63 & $\mathbf{2 . 0 4}$ & $\mathbf{1 . 5 7}$ & $\mathbf{2 . 6 1}$ \\
& SL with others (UL or CL) & 7 & 2.27 & 0.90 & 4.71 \\
\multirow{2}{*}{ UL } & Only UL & 28,367 & $\mathbf{1 . 9 4}$ & $\mathbf{1 . 9 2}$ & $\mathbf{1 . 9 7}$ \\
& UL with others (SL or CL) & 2088 & $\mathbf{1 . 7 2}$ & $\mathbf{1 . 6 5}$ & $\mathbf{1 . 8 0}$ \\
$\mathrm{CL}$ & Only CL & 46,157 & $\mathbf{1 . 8 2}$ & $\mathbf{1 . 8 1}$ & $\mathbf{1 . 8 4}$ \\
& CL with others (UL or SL) & 2800 & $\mathbf{1 . 5 9}$ & $\mathbf{1 . 5 3}$ & $\mathbf{1 . 6 5}$ \\
\hline
\end{tabular}

Bold type: $95 \% \mathrm{Cl}$ does not include 1.00

$O$ observed number of cases, SIR standardized incidence ratio, $\mathrm{Cl}$ confidence

interval, SL sialolithiasis, UL urolithiasis, $C L$ cholelithiasis

shared risk or susceptibility factors, and these can be also tested in the family setting. Spouses share environmental risk factors, which may be shared to a lesser extent also by first-degree family members, in addition to the shared genes. We thus wanted to approach the issue of comorbidity in the family setting which is not sensitive to surveillance bias to the same degree as comorbidities in the same individual. Another motivation of the present study was the lack of literature on familial SL. Even though SL is a rare disease we were able to identify over 8000 patients through the nation-wide registers. The reported chemical similarities between SL and kidney stone might implicate similar mechanisms of stone formation. The strengths of the study were its nation-wide scope, medical diagnostics of stone diseases and complete family records obtained from the Multigeneration Register essentially covering the Swedish population over a century [19]. The limitation was the lack of access to primary health care records.

The novel familial data on concordant SL showed a familial risk higher (2.06) than that for UL (1.94) or CL (1.82). Female risks where somewhat higher than male risks ( 2.15 vs. 1.95 ) which was also the case for UL but not for CL. Concordant familial risks for UL are well documented in the literature $[9,21-23]$. Also many genes contributing to susceptibility to UL are known and these encode rare metabolic factors, including disturbances in calcium and oxalate balance [24-26]. However, for
CL earlier studies were mainly based on case-control design which may have inaccuracies in reporting of cases in family members [27-29]. Several genes predisposing to CL have been identified and these include variants encoding apolipoproteins, lipid receptors and proteins involved in cholesterol metabolism $[10,11]$.

Correlation between spouses was marginal although between UL and CL the SIR of 1.10 was statistically significant. This could be explained by known risk factors, such as obesity and physical inactivity. Such low correlations suggest that surveillance bias may contribute to the reported comorbidities. Familial risks between stone diseases were also modest and they were not significant between SL and UL for which the stone composition is similar [1]. The SIR between UL and CL was 1.17, somewhat higher than the SIR between spouses which may imply minor sharing of genetic susceptibility. Similarly the SIRs between SL and CL (1.10 and 1.14) were at least statistically significant. Shared risk factors between these stone diseases could be inflammation and diabetes. Further evidence on unique familial clustering of each stone disease was shown for risks with family histories of a single stone disease which for UL and CL were higher than those with family histories of multiple stone diseases. Although explaining such small familial risks between stone diseases is speculative, they nevertheless provide another argument against shared disease mechanisms underlying the reported comorbidities.

The study covered a time span of 29 years and it is appropriate to consider to what extent diagnostic modalities and techniques might have changed over time. Diagnosis of SL is usually made by characteristic history and physical examination, confirmed by $\mathrm{x}$-ray or by ultrasound. For UL $\mathrm{x}$-ray examination was the standard diagnostic modality in the early period but it was replaced by computerized tomography (CT) by around year 2000 as the primary modality. For CL abdominal ultrasound and CT are the standard diagnostic tools. In Sweden, the number of CT instruments increased over the study period from 85 by 1989 to 200 by 2010 [30]. Undoubtedly also ultrasound technologies have improved over the study period. However, how improvements in diagnostic modalities might influence

Table 5 Risk of $S L, U L$, and $C L$ in spouses

\begin{tabular}{|c|c|c|c|c|c|c|c|c|c|c|c|c|c|}
\hline \multirow{3}{*}{$\begin{array}{l}\text { Risk in } \\
\text { spouse }\end{array}$} & \multirow{3}{*}{$\begin{array}{l}\text { Spouse } \\
\text { history }\end{array}$} & \multicolumn{4}{|c|}{ Husbands } & \multicolumn{4}{|l|}{ Wives } & \multicolumn{4}{|l|}{ All } \\
\hline & & \multirow{2}{*}{$\begin{array}{l}0 \\
100\end{array}$} & \multirow{2}{*}{$\begin{array}{l}\text { SIR } \\
\mathbf{1 . 2 6}\end{array}$} & \multicolumn{2}{|c|}{$95 \% \mathrm{Cl}$} & \multirow{2}{*}{$\begin{array}{l}0 \\
200\end{array}$} & \multirow{2}{*}{$\frac{S I R}{1.01}$} & \multicolumn{2}{|c|}{$95 \% \mathrm{Cl}$} & \multirow{2}{*}{$\begin{array}{l}0 \\
300\end{array}$} & \multirow{2}{*}{$\begin{array}{l}\text { SIR } \\
1.08\end{array}$} & \multicolumn{2}{|c|}{$95 \% \mathrm{Cl}$} \\
\hline & & & & 1.03 & 1.53 & & & 0.88 & 1.16 & & & 0.96 & 1.21 \\
\hline$S L$ & $\mathrm{CL}$ & 37 & 0.82 & 0.58 & 1.13 & 69 & 1.20 & 0.93 & 1.51 & 106 & 1.03 & 0.84 & 1.25 \\
\hline UL & $S L$ & 200 & 1.00 & 0.86 & 1.15 & 100 & 1.26 & 1.02 & 1.53 & 300 & 1.07 & 0.95 & 1.20 \\
\hline UL & $\mathrm{CL}$ & 9153 & 1.10 & 1.07 & 1.12 & 995 & 1.12 & 1.05 & 1.19 & 10,148 & 1.10 & 1.08 & 1.12 \\
\hline$C L$ & $S L$ & 69 & 1.18 & 0.92 & 1.50 & 37 & 0.81 & 0.57 & 1.11 & 106 & 1.02 & 0.83 & 1.23 \\
\hline $\mathrm{CL}$ & UL & 995 & 1.12 & 1.05 & 1.20 & 9153 & 1.10 & 1.08 & 1.13 & 10,148 & 1.10 & 1.08 & 1.13 \\
\hline
\end{tabular}

Bold type: $95 \%$ confidence interval does not include 1.00

$O$ observed number of cases, SIR standardized incidence ratio, $C l$ confidence interval, SL sialolithiasis, UL urolithiasis, CL cholelithiasis 
incident patient numbers cannot be predicted because higher precision may add new cases but remove false diagnoses. In Fig. 1 the incident rate for CL was stable over the period while for SL and UL the rates appeared to be declining. The interpretation of the rates is not simple because for SL and UL a large number of patients were seen in outpatient care and because we have no data on patients seen in primary care.

\section{Conclusions}

The Swedish nation-wide data show high familial risks for each of the concordant stone diseases, and for SL the research findings were entirely novel. Risks between stone diseases among spouses were low and significant only for UL and CL. Familial risks between stone diseases were also low but higher than risks between spouses. Our findings show that familial clustering is unique to each stone disease and further indicate that the underlying disease mechanisms are distinct. The results cast doubt on excessive comorbidities between these three stone diseases.

\section{Abbreviations}

Cl: Confidence interval; CL: Cholelithiasis; OR: Odds ratio; SIR: Standardized incidence ratio; SL: Sialolithiasis; UL: Urolithiasis

\section{Funding}

This project was supported by grants from the Swedish Research Council (2014-2517, 2014-10134 and 2016-01176), as well as ALF funding from Region Skåne.

\section{Availability of data and materials}

Need approval of the Swedish health authorities.

\section{Authors' contributions \\ $\mathrm{KH}$ had full access to all of the data in the study and takes responsibility for the integrity of the data and the accuracy of the data analysis. Study concept and design: $\mathrm{KH}, \mathrm{OH}, \mathrm{AK}, \mathrm{XL}$. Statistical analysis: XL. Acquisition, analysis, or interpretation of data: $\mathrm{KS}, \mathrm{JS}, \mathrm{KH}, \mathrm{OH}, \mathrm{AK}, \mathrm{AF}, \mathrm{XL}$. Drafting of the manuscript: $\mathrm{KH}, \mathrm{OH}$. Critical revision of the manuscript for important intellectual content: KS, AF, OH. Final approval of the manuscript for publication: all authors.}

\section{Ethics approval and consent to participate}

The study was approved by the Regional Ethical Review Board of Lund University (no. 2012/795). No informed consent was required because the study used anonymous data from national health records over several decades.

\section{Consent for publication}

Not relevant.

\section{Competing interests}

The authors declare that they have no competing interests.

\section{Publisher's Note}

Springer Nature remains neutral with regard to jurisdictional claims in published maps and institutional affiliations.

\section{Author details}

'Division of Molecular Genetic Epidemiology, German Cancer Research Center (DKFZ), Im Neuenheimer Feld 580, D-69120 Heidelberg, Germany. ${ }^{2}$ Center for Primary Health Care Research, Lund University, 20502 Malmö, Sweden. ${ }^{3}$ Department of Urology, Helsinki University Hospital, Helsinki, Finland. ${ }^{4}$ Cancer Gene Therapy Group, Faculty of Medicine, University of
Helsinki, Helsinki, Finland. ${ }^{5}$ Department of Otorhinolaryngology, Helsinki University Hospital, Helsinki, Finland. ${ }^{6}$ Department of Family Medicine and Community Health, Population Health Science and Policy, Icahn School of Medicine at Mount Sinai, New York, USA. ${ }^{7}$ Department of Functional Pathology, Center for Community-based Healthcare Research and Education (CoHRE), School of Medicine, Shimane University, Matsue, Japan.

Received: 5 March 2018 Accepted: 10 June 2018

Published online: 03 July 2018

\section{References}

1. Rakesh N, Bhoomareddy Kantharaj YD, Agarwal M, Agarwal K. Ultrastructural and elemental analysis of sialoliths and their comparison with nephroliths. J Investig Clin Dent. 2014:5(1):32-7.

2. Delli K, Spijkervet FK, Vissink A. Salivary gland diseases: infections, sialolithiasis and mucoceles. Monogr Oral Sci. 2014;24:135-48.

3. Sigismund PE, Zenk J, Koch M, Schapher M, Rudes M, Iro H. Nearly 3,000 salivary stones: some clinical and epidemiologic aspects. Laryngoscope. 2015;125(8):1879-82

4. Schroder SA, Andersson M, Wohlfahrt J, Wagner N, Bardow A, Homoe P. Incidence of sialolithiasis in Denmark: a nationwide population-based register study. Eur Arch Otorhinolaryngol. 2017;274(4):1975-81.

5. Wilson KF, Meier JD, Ward PD. Salivary gland disorders. Am Fam Physician. 2014:89(11):882-8

6. Bullock KN. Parotid and submandibular duct calculi in three successive generations of one family. Postgrad Med J. 1982;58(675):35-6.

7. Tiselius HG. Epidemiology and medical management of stone disease. BJU Int. 2003;91(8):758-67.

8. Morgan MS, Pearle MS. Medical management of renal stones. BMJ. 2016;352:52.

9. Hemminki K, Hemminki O, Forsti A, Sundquist K, Sundquist J, Li X. Familial risks in urolithiasis in the population of Sweden. BJU Int. 2018;121(3):479-85.

10. Stinton $L M$, Shaffer EA. Epidemiology of gallbladder disease: cholelithiasis and cancer. Gut and liver. 2012;6(2):172-87.

11. Lammert F, Gurusamy K, Ko CW, Miquel JF, Mendez-Sanchez N, Portincasa P, van Erpecum KJ, van Laarhoven CJ, Wang DQ. Gallstones. Nat Rev Dis Primers. 2016;2:16024.

12. Hemminki K, Hemminki O, Forsti A, Sundquist $K$, Sundquist J, Li X. Familial risks for gallstones in the population of Sweden. BMJ Open Gastroenterol. 2017:4(1):e000188

13. Krawczyk M, Stokes CS, Lammert F. Genetics and treatment of bile duct stones: new approaches. Curr Opin Gastroenterol. 2013;29(3):329-35.

14. Wu CC, Hung SH, Lin HC, Lee CZ, Lee HC, Chung SD. Sialolithiasis is associated with nephrolithiasis: a case-control study. Acta Otolaryngol. 2016;136(5):497-500.

15. Hung SH, Lin HC, Su CH, Chung SD. Association of sialolithiasis with cholelithiasis: a population-based study. Head Neck. 2016;38(4):560-3.

16. Li CH, Sung FC, Wang YC, Lin D, Kao CH. Gallstones increase the risk of developing renal stones: a nationwide population-based retrospective cohort study. QJM. 2014;107(6):451-7.

17. Taylor EN, Chan AT, Giovannucci EL, Curhan GC. Cholelithiasis and the risk of nephrolithiasis. J Urol. 2011;186(5):1882-7.

18. Hemminki K, Hemminki O, Försti A, Sundquist K, Sundquist J, Li X Surveillance bias in cancer risk after unrelated medical conditions: example urolithiasis. Sci Rep. 2017:7:8073.

19. Hemminki K, Ji J, Brandt A, Mousavi SM, Sundquist J. The Swedish familyCancer database 2009: prospects for histology-specific and immigrant studies. Int J Cancer. 2010;126:2259-67.

20. Frank C, Fallah M, Ji J, Sundquist J, Hemminki K. The population impact of familial cancer, a major cause of cancer. Int J Cancer. 2014;134:1899-906.

21. Curhan GC, Willett WC, Rimm EB, Stampfer MJ. Family history and risk of kidney stones. J Am Soc Nephrol. 1997;8(10):1568-73.

22. Stechman MJ, Loh NY, Thakker RV. Genetic causes of hypercalciuric nephrolithiasis. Pediatr Nephrol. 2009;24(12):2321-32.

23. Edvardsson VO, Palsson R, Indridason OS, Thorvaldsson S, Stefansson K. Familiality of kidney stone disease in Iceland. Scand J Urol Nephrol. 2009;43(5):420-4.

24. Edvardsson VO, Goldfarb DS, Lieske JC, Beara-Lasic L, Anglani F, Milliner DS, Palsson R. Hereditary causes of kidney stones and chronic kidney disease. Pediatr Nephrol. 2013;28(10):1923-42.

25. Sayer JA. Progress in understanding the genetics of calcium-containing nephrolithiasis. J Am Soc Nephrol. 2017;28:748-59. 
26. Taguchi K, Yasui T, Milliner DS, Hoppe B, Chi T. Genetic risk factors for idiopathic urolithiasis: a systematic review of the literature and causal network analysis. Eur Urol Focus. 2017;3(1):72-81.

27. Sarin SK, Negi VS, Dewan R, Sasan S, Saraya A. High familial prevalence of gallstones in the first-degree relatives of gallstone patients. Hepatol. 1995;22(1):138-41.

28. Nakeeb A, Comuzzie AG, Martin L, Sonnenberg GE, Swartz-Basile D, Kissebah AH, Pitt HA. Gallstones: genetics versus environment. Ann Surg. 2002;235(6):842-9.

29. Hsing AW, Bai Y, Andreotti G, Rashid A, Deng J, Chen J, Goldstein AM, Han $T Q$, Shen MC, Fraumeni JF Jr, et al. Family history of gallstones and the risk of biliary tract cancer and gallstones: a population-based study in shanghai, China. Int J Cancer. 2007;121(4):832-8.

30. Hemminki K, Liu H, Hemminki A, Sundquist J. Power and limits of modern cancer diagnostics: cancer of unknown primary. Ann Oncol. 2012;23:760-4.

Ready to submit your research? Choose BMC and benefit from:

- fast, convenient online submission

- thorough peer review by experienced researchers in your field

- rapid publication on acceptance

- support for research data, including large and complex data types

- gold Open Access which fosters wider collaboration and increased citations

- maximum visibility for your research: over $100 \mathrm{M}$ website views per year 